\title{
Acuíferos sustentables: conceptos, mitos y percepciones
}

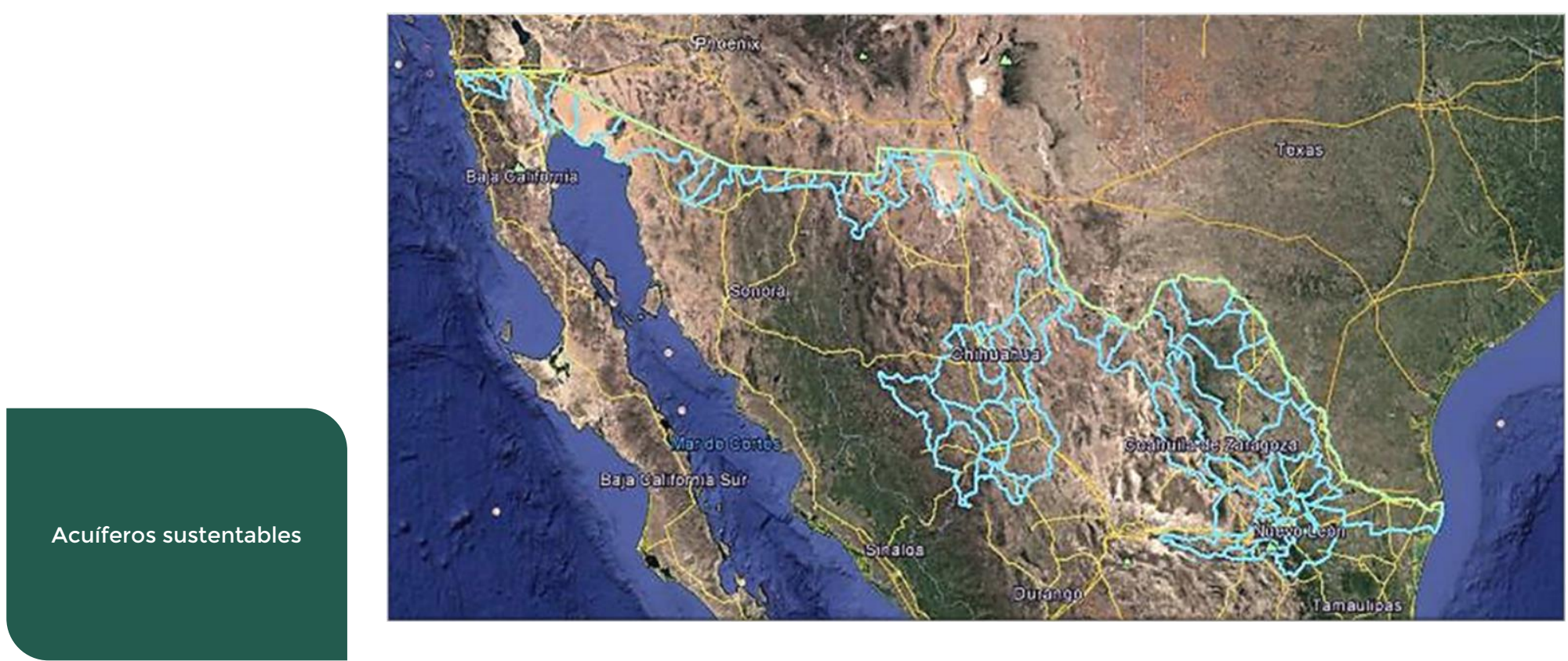

La sustentabilidad hídrica de las cuencas y acuíferos depende en gran medida de aspectos cuantitativos y cualitativos.

La sustentabilidad hídrica de las cuencas y acuíferos depende en gran medida de aspectos cuantitativos (ej. disminución de caudales mínimos y abatimiento de niveles piezométricos) y cualitativos (presencia de contaminantes, pérdida continua de nutrientes), entre otros. A nivel global, un número importante de acuíferos han registrado una caída en su disponibilidad hídrica, evidenciada a través de mediciones in situ (1) u observaciones mediante percepción remota (2).

Si bien el agua es un recurso natural considerado como renovable, existen sistemas de agua subterránea a nivel regional y local, cuyas características geológicas han dado lugar a almacenamientos confinados, localizados a profundidades que van de cientos a miles de metros. Debido a las condiciones climáticas actuales, la mayor parte de estos sistemas han sido y siguen siendo explotados en zonas áridas y semiáridas, ante la falta de otras fuentes alternativas existentes como los arroyos, ríos o lagos. Una característica importante de algunos de estos sistemas radica en el tiempo de renovación de sus aguas subterráneas, también conocidas como fósiles, cuya edad remonta al inicio del holoceno (hace 12,000 años aproximadamente). Por lo general, en estos acuíferos las tasas de extracción de agua actuales 
PERSPECTIVAS IMTA (0)

$N^{\circ} .2,2020$

sobrepasan la recarga (ocurrida hace cientos o miles de años) de estos sistemas, lo cual se ha reflejado en el declive de su volumen almacenado.

La explotación de las aguas fósiles para diferentes usos (como es el caso del acuífero de la Ciudad de México, o el acuífero del norte del Sahara para fines de riego) ha generado controversia respecto a la sostenibilidad de dichos sistemas a largo plazo. Dicha discusión ha llevado a realizar estudios importantes para determinar el origen del agua subterránea, así como para cuantificar el tiempo de residencia de las aguas subterráneas en dichos acuíferos, esto es, la edad del recurso hídrico que se está extrayendo para satisfacer las diferentes actividades que la sociedad requiere. Recientemente, se estimó que aproximadamente el 6 por ciento del agua subterránea en los 2000 m más someros de la superficie terrestre tiene una edad menor a los 50 años. El 94 por ciento restante, con un volumen equivalente a 21 millones de kilómetros cúbicos, es el resultado de los mecanismos de recarga ocurrida hace más de 50 años. Estas cifras nos dan una perspectiva acerca de la distribución de edad del agua subterránea, en donde las aguas viejas y fósiles predominan dentro de los sistemas de aguas subterráneas (3).

El conocimiento de la composición de las diferentes edades del agua dentro del mismo acuífero (por lo general, a mayor profundidad, mayor edad) ha favorecido a crear el mito de que la sustentabilidad hídrica se mida en función de la edad y tiempo de residencia de su volumen extraído. Sin embargo, la reciente evidencia sobre el dinamismo de los sistemas de agua subterránea y sus vastos volúmenes de almacenamiento han Ilevado a proponer un cambio de paradigma (5) acerca de la sostenibilidad de las aguas subterráneas basándose en indicadores más constructivos como la estabilidad de los niveles piezométricos, la calidad del agua y los caudales ambientales.

El Instituto Mexicano de Tecnología del Agua cuenta con el conocimiento y la infraestructura necesaria para emprender este tipo de estudios vitales que ayuden a comprender mejor las aguas subterráneas de nuestro país y así mejorar la planeación y gestión de los acuíferos dentro de un contexto más sostenible.

Para saber más del tema

(1) Döll, P., H. Müller Schmied, C. Schuh, F.T. Portmann, and A. Eicker (2014), Global-scale assessment of groundwater depletion and related groundwater abstractions: Combining hydrological modeling with information from well observations and GRACE satellites, Water Resour.Res., 50, 5698-5720, doi:10.1002/2014WR015595

(2) Famiglietti, J. S. (2014), The global groundwater crisis, Nat. Clim. Change, 4(11), 945-948, doi:10.1038/nclimate2425.

(3) Gleeson, T., Befus, K. M., Jasechko, S., Luijendijk, E., \& Cardenas, M. B. (2016). The global volume and distribution of modern groundwater. Nature Geoscience, 9(2), 161.

(4) Ferguson, G., Cuthbert M. O., Befus, K., Gleeson, T., \& McIntosh, J. C. (2020). The groundwater age-sustainability myth. Preprint submitted to EarthArXiv. 